\title{
Cytoplasm estrogen receptor $\beta 5$ as an improved prognostic factor in thymoma and thymic carcinoma progression
}

\author{
SHENG-YING LI* , YU-XIA WANG* ${ }^{*}$ LEI WANG, ZHI-BING QIAN and MING-LI JI \\ Department of Physiology, Basic Medical College of Xinxiang Medical University, Xinxiang, Henan 453003, P.R. China
}

Received May 24, 2014; Accepted July 23, 2015

DOI: $10.3892 / 01.2015 .3555$

\begin{abstract}
A number of previous studies have reported that sex steroid hormones, including estrogens, are involved in the regulation of the thymic function. The aim of the present study was to investigate the expression of estrogen receptor $\beta 5$ (ER $\beta 5)$ in thymic tumors and the correlation between ER $\beta 5$ expression and thymoma biological characteristics. The expression levels of ER $\beta 5$ in thymic epithelial tumors was evaluated in 103 patents using immunohistochemical staining and reverse transcription-quantitative polymerase chain reaction. In addition, an indirect immunofluorescence assay was performed to evaluate the ER $\beta 5$ expression levels in the TC1889 and T1682 cell lines. The survival outcome was estimated using Kaplan-Meier plots. The results indicated that ER $\beta 5$ expression was mainly located in the thymic tumor cell cytoplasm (87.37\%; 90/103 cases) and overexpression was observed in thymic tumors compared with normal thymic tissues $(\mathrm{P}=0.001)$. Using the Kruskal-Wallis test, a statistically significant association was observed between cytoplasmic ER $\beta 5$ (cER $\beta 5$ ) expression and thymic tumor subtypes $(\mathrm{P}=0.024)$ and stages $(\mathrm{P}=0.003$ and $\mathrm{R}=-0.376)$. The Kaplan-Meier plots revealed that cER $\beta 5$ expression was significantly associated with improved overall and progression-free survival $(\mathrm{P}=0.008$ and $\mathrm{P}=0.004$, respectively). The present study suggested that overexpression of cER $\beta 5$ may indicate an improved prognosis and may be involved in the underlying mechanism through which estrogen inhibits thymoma and thymic carcinoma development.
\end{abstract}

\section{Introduction}

The ability of sex hormones to affect lymphocyte development is well-known (1-3), and particularly the ability of

Correspondence to: Professor Ming-Li Ji, Department of Physiology, Basic Medical College of Xinxiang Medical University, 601 Jin Sui Road, Red Zone, Xinxiang, Henan 453003, P.R. China E-mail: limingjdoc@163.com

*Contributed equally

Key words: thymic tumors, thymic carcinomas, estrogen receptor $\beta 5$, TC1889 cells, T1682 cells, prognosis estrogen to inhibit postnatal thymocyte development (3-6). Extended exposure to sex steroid hormones, for instance during estrogen therapy and pregnancy, results in thymic atrophy and loss of cellularity in humans and animals (3). The estrogen-triggered thymic atrophy may result in sexual dimorphism in the immune response and downregulation of autoimmune responses (7-9). A number of studies have reached the conclusion that estrogen induces thymic atrophy, and certain studies have demonstrated that estrogen may affect the development of thymomas and thymic carcinomas (9-11). However, verification of such findings is not possible due to limited data, and the expression and distribution of estrogen receptors in thymomas and thymic carcinomas remain controversial (10-12). In addition, the biological effect of estrogen is unclear. Estrogen has been demonstrated to exhibit pleiotropic effects by binding to intracellular receptors, including estrogen receptors (ER) $\alpha$ and $\beta$. Previous meta-analyses observed that ER $\alpha$ was not overexpressed in thymic tumors (including thymomas and thymic carcinomas) compared with in benign thymic tissues, whereas ER $\beta$ was overexpressed, which may indicate binding to ER $\beta$ and complex estrogen physiological effects $(12,13)$.

$\mathrm{ER} \beta$ has at least five variant isoforms (ER $\beta 1-5)$, which have been described in numerous human organs or tissues, including breast and prostate cancer (13-15). Notably, no evident structural differences exist among these variants, for example they all lack certain key parts, such as helix 12, however, regarding their function and distribution, certain differences have been identified; ER $\beta 2$ is mainly located in the nucleus whereas ER $\beta 5$ is mainly found in the cytoplasm in cancer tissues $(13,14)$.

Therefore, the present study aimed to investigate the expression and distribution of ER $\beta 5$ in thymomas and thymic carcinomas, and further analyze the correlation between ER $\beta 5$ expression and prognostic factors.

\section{Patients and methods}

Patient tissue specimens and reagents. Specimens from 103 thymoma and thymic carcinoma patients, who had undergone thymectomy between 1999 and 2010, were obtained from the Basic Medical College of Xinxiang Medical University (Xinxiang, China). The study was approved by the Ethics Committee of the Basic Medical College of Xinxiang Medical University, and all patients 
Table I. Expression of nuclear and cytoplasmic ER $\beta 5$ in thymic tumor and normal tissues.

\begin{tabular}{|c|c|c|c|c|c|c|c|c|c|c|}
\hline \multirow[b]{2}{*}{ Groups } & \multicolumn{4}{|c|}{$\mathrm{cER} \beta 5, \mathrm{n}$} & \multirow[b]{2}{*}{ P-value } & \multicolumn{4}{|c|}{$\mathrm{nER} \beta 5, \mathrm{n}$} & \multirow[b]{2}{*}{ P-value } \\
\hline & - & + & ++ & +++ & & - & + & ++ & +++ & \\
\hline Thymic tumor & 13 & 18 & 49 & 23 & 0.001 & 76 & 20 & 6 & 1 & 0.112 \\
\hline Normal & 18 & 5 & 1 & 2 & & 22 & 2 & 1 & 1 & \\
\hline Total & 31 & 23 & 50 & 25 & & 98 & 22 & 7 & 2 & \\
\hline
\end{tabular}

ER $\beta 5$, estrogen receptor $\beta 5$; cER $\beta 5$, cytoplasmic ER $\beta 5$; nER $\beta 5$, nuclear ER $\beta 5$.

provided informed consent for the use of their samples. All patient characteristics (including gender and age) and tumor clinical data were collected. The patient sample included 68 male and 35 females, with a mean age of 50 years (range, 41-65 years). According to the histological criteria of the WHO classification (16), the thymoma tumor subtypes were as follows: 21 cases of type A; 23 cases of type AB; 12 cases of type B1; 15 cases of type B2 and 9 cases of type B3 thymomas. In addition, 23 cases of stage I-IV thymic carcinomas were identified, according to Masaoka staging (17). The normal thymi of 26 children were used as controls (mean age, 11 years; age range, 8-15 years), representing the ER $\beta 5$ expression levels in normal tissues. Survival data, including the overall survival (OS) and progression-free survival (PFS) rates, were recorded. OS was defined as the time (months) between the primary surgical treatment and mortality associated with the thymic tumor. PFS was defined as the interval (months) between the primary surgical treatment and the initial locoregional or distant recurrence.

Monoclonal mouse anti-human ER $\beta 5$ antibody (clone 5/25; product code, MCA4676T) was obtained from Bio-Rad Laboratories, Inc. (Hercules, CA, USA). FITC-conjugated goat anti-human IgG antibody was purchased from Santa Cruz Biotechnology, Inc., (Dallas, TX, USA). Horseradish peroxidase-conjugated goat anti-mouse IgG was obtained from Cell Signaling Technology, Inc. (Danvers, MA, USA). The thymic carcinoma cell line, TC1889, and the thymoma cell line, T1682, were established, characterized and verified as previously described (18).

Immune microarray and evaluation of immunoreactivity. Tissue microarrays (TMAs) were constructed from the paraffin-embedded blocks of the 129 thymic specimens, using a tissue array device (cat. no. BNSW-001_TY9184; Shanghai Outdo Biotech Co., Ltd., Shanghai, China). Representative tumor areas were marked in each paraffin-embedded specimen and at least two areas were sampled. The diameter of the tissue cylinders was $0.6 \mathrm{~mm}$, made using tissue chip drilling apparatus (Shanghai Outdo Biotech Co., Ltd.). For ER $\beta 5$ staining, the monoclonal ER $\beta 5$ antibody (clone 5/25) was used at a dilution of 1:50, which was demonstrated to be highly specific in immunohistochemical assays performed in this study. Antigen retrieval was performed in $0.01 \mathrm{~mol} / 1$ sodium citrate buffer ( $\mathrm{pH}$ 6.0) in the microwave for $15 \mathrm{~min}$. To establish the negative controls, the same procedure was followed, without the primary antibody. A previously described scoring system was adopted (19), the tissue microarrays were digitized and cytoplasmic ER $\beta 5$ (cER $\beta 5)$ or nuclear ER $\beta 5$ (nER $\beta 5)$ immunoreactivity was scored between - and +++ (-, no staining; + , weak staining; ++ , moderate staining; +++ , strong staining). The percentage of tumor cells displaying staining for cER $\beta 5$ or nER $\beta 5$ was determined and calculated as the average of six high power fields per specimen. The cases were scored independently by three specialists and discordant results were re-evaluated to reach consensus.

Indirect immunofluorescence assay (IIFA). TC1889 and T1682 cells were cultured in RPMI-media containing HEPES supplemented with $10 \%$ fetal calf serum and $1 \%$ penicillin/streptomycin (Sigma-Aldrich) in an atmosphere containing $5 \% \mathrm{CO}_{2}$ at $37^{\circ} \mathrm{C}$. For IIFA, the anti-ER $\beta 5$ antibody (clone 5/25) was incubated at a dilution of $1: 500$ at $4^{\circ} \mathrm{C}$ overnight. Fluorescein isothiocyanate-conjugated goat anti-human immunoglobulin G (Santa Cruz Biotechnology, Inc., Santa Cruz, CA, USA) was used as the secondary antibody and incubated at a dilution of 1:100 for $1 \mathrm{~h}$ at room temperature. Cells were washed with phosphate-buffered saline (J-H Biotechnology Ltd., Shanghai, China) and mounted using $10 \mathrm{mg} / \mathrm{ml}$ DAPI (Sigma-Aldrich) in aqueous mountant (Dako North America, Inc., Carpinteria, CA, USA). A fluorescence microscope (Leica DM1000; Leica Microsystems GmbH, Wetzlar, Germany) was used for examination of the samples.

Reverse transcription-quantitative polymerase chain reaction $(R T-q P C R)$. Total RNA was extracted using the RNeasy mini kit (Qiagen, Crawley, UK) with additional purification by centrifugation at $12,000 \mathrm{x} \mathrm{g}$ for $15 \mathrm{~min}$ through QIAshredder spin columns (Qiagen). The total RNA concentration and purity were calculated using the Nanodrop system (Labtech International Ltd., Lewes, UK). Subsequently, cDNA synthesis was performed using the SYBR ${ }^{\circledR}$ ExScript RT-PCR kit (Takara Biotechnology Co., Ltd., Dalian, China) according to the manufacturer's instructions. Quantitative PCR was performed using the SYBR $^{\circledR}$ Premix Ex Taq ${ }^{\mathrm{TM}}$ II kit (Takara Biotechnology Co., Ltd.) with a LightCycler system (Roche Diagnostics, Basel, Switzerland). The primers used were as follows: ER $\beta 5$ forward, 5'-CGGAAGCTGGCTCACTTGCT-3', and reverse, 5'-CTTCACCCTCCGTGGAGCAC-3'; and $\beta$-actin forward, 5'-GTGGGGCGCCCAGGCACCAC-3', and reverse, 5'-CTCCTTAATGTCACGCACGATTT-3'. The reaction volume was $50 \mu \mathrm{l}$ and comprised the following final 
Table II. Correlation between cytoplasmic and nuclear ER $\beta 5$ expression and patient characteristics.

\begin{tabular}{|c|c|c|c|c|c|c|}
\hline \multirow[b]{2}{*}{ Characteristic } & \multicolumn{2}{|c|}{$\mathrm{nER} \beta 5, \mathrm{n}$} & \multirow[b]{2}{*}{ P-value } & \multicolumn{2}{|c|}{$\mathrm{cER} \beta 5, \mathrm{n}$} & \multirow[b]{2}{*}{ P-value } \\
\hline & - & + & & - & + & \\
\hline Gender & & & 0.131 & & & 0.245 \\
\hline Male & 48 & 20 & & 7 & 61 & \\
\hline Female & 29 & 6 & & 6 & 29 & \\
\hline Age & & & 0.576 & & & 0.514 \\
\hline$<50$ years & 10 & 3 & & 2 & 11 & \\
\hline$\geq 50$ years & 67 & 23 & & 11 & 79 & \\
\hline Tumor size & & & 0.132 & & & 0.614 \\
\hline$<6 \mathrm{~cm}$ & 27 & 13 & & 5 & 35 & \\
\hline$\geq 6 \mathrm{~cm}$ & 50 & 13 & & 8 & 55 & \\
\hline
\end{tabular}

ER $\beta 5$, estrogen receptor $\beta 5$; cER $\beta 5$, cytoplasmic ER $\beta 5$; nER $\beta 5$, nuclear ER $\beta 5$.

Table III. Correlation between cytoplasmic ER $\beta 5$ expression and tumor pathological characteristics.

\begin{tabular}{|c|c|c|c|c|c|c|}
\hline \multirow[b]{2}{*}{ Pathological classification } & \multicolumn{4}{|c|}{$\operatorname{cER} \beta 5$} & \multirow[b]{2}{*}{ P-value ${ }^{a}$} & \multirow[b]{2}{*}{ R-value ${ }^{b}$} \\
\hline & - & + & ++ & +++ & & \\
\hline Tumor subtype & & & & & 0.024 & 0.088 \\
\hline A & 4 & 3 & 9 & 5 & & \\
\hline $\mathrm{AB}$ & 5 & 0 & 13 & 5 & & \\
\hline B 1 & 3 & 0 & 5 & 4 & & \\
\hline B2 & 1 & 6 & 7 & 1 & & \\
\hline B3 & 0 & 4 & 2 & 3 & & \\
\hline $\mathrm{C}$ & 0 & 5 & 13 & 5 & & \\
\hline Clinical stage & & & & & 0.003 & -0.376 \\
\hline I & 0 & 0 & 2 & 8 & & \\
\hline II & 3 & 5 & 25 & 9 & & \\
\hline III & 5 & 10 & 16 & 3 & & \\
\hline IV & 5 & 3 & 5 & 4 & & \\
\hline
\end{tabular}

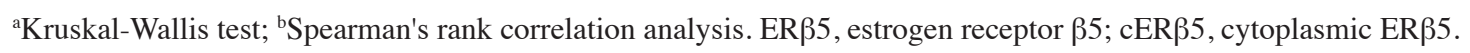

quantities/concentrations: $1,000 \mathrm{ng}$ ER $\beta 5$ or $100 \mathrm{ng} \beta$-actin cDNA, $0.2 \mu \mathrm{M}$ of each primer, $1 \mathrm{U}$ AmpliTaq Gold DNA polymerase (Life Technologies, Grand Island, NY, USA), $1.5 \mathrm{mM} \mathrm{MgCl}_{2}$ and $200 \mu \mathrm{M}$ deoxynucleotide triphosphate. The cycling conditions included a denaturation step at $94^{\circ} \mathrm{C}$ for $10 \mathrm{~min}, 45$ cycles (for ER $\beta 5$ ) or 25 cycles (for $\beta$-actin; RNA input) at $94^{\circ} \mathrm{C}$ for $45 \mathrm{sec}, 55^{\circ} \mathrm{C}$ for $60 \mathrm{sec}$ and $72^{\circ} \mathrm{C}$ for $45 \mathrm{sec}$, and a final extension step at $72^{\circ} \mathrm{C}$ for $10 \mathrm{~min}$. For each primer, serial dilutions of a standard cDNA were amplified to create a standard curve, and values of unknown samples were estimated relative to this standard curve in order to assess the PCR efficiency. Threshold cycle $(\mathrm{Ct})$ values were collected for $\beta$-actin and the genes of interest during log phase of the cycle. Gene of interest levels were normalized to $\beta$-actin for each sample $[\Delta \mathrm{Ct}=\mathrm{Ct}($ gene of interest $)-\mathrm{Ct}(\beta$-actin $)]$. The samples were resolved on $2 \%$ agarose gel and transferred to a nylon transfer membrane (Hybond-N+; GE Healthcare Life
Sciences, Chalfont, UK). Samples were then analyzed using ABI PRISM 7000 SDS Software (Applied Biosystems Life Technologies, Foster City, CA, USA).

Statistical analysis. Mann-Whitney U test, Kruskal-Wallis test and Spearman's rank correlation were performed using the SAS software (version 9.12; SAS Institute Inc., Cary, NC, USA). Associations with OS were initially analyzed by Kaplan-Meier plots (log-rank test). $\mathrm{P}<0.05$ was considered to indicate a statistically significant difference.

\section{Results}

Expression of ER $\beta 5$ in thymic tumors and normal thymic tissues. The results of the ER $\beta 5$ immunohistochemical assay for the 129 cases are listed in Tables I-III. The majority of thymic tumors exhibited ER $\beta 5$-positive staining (99.02\%; 
A
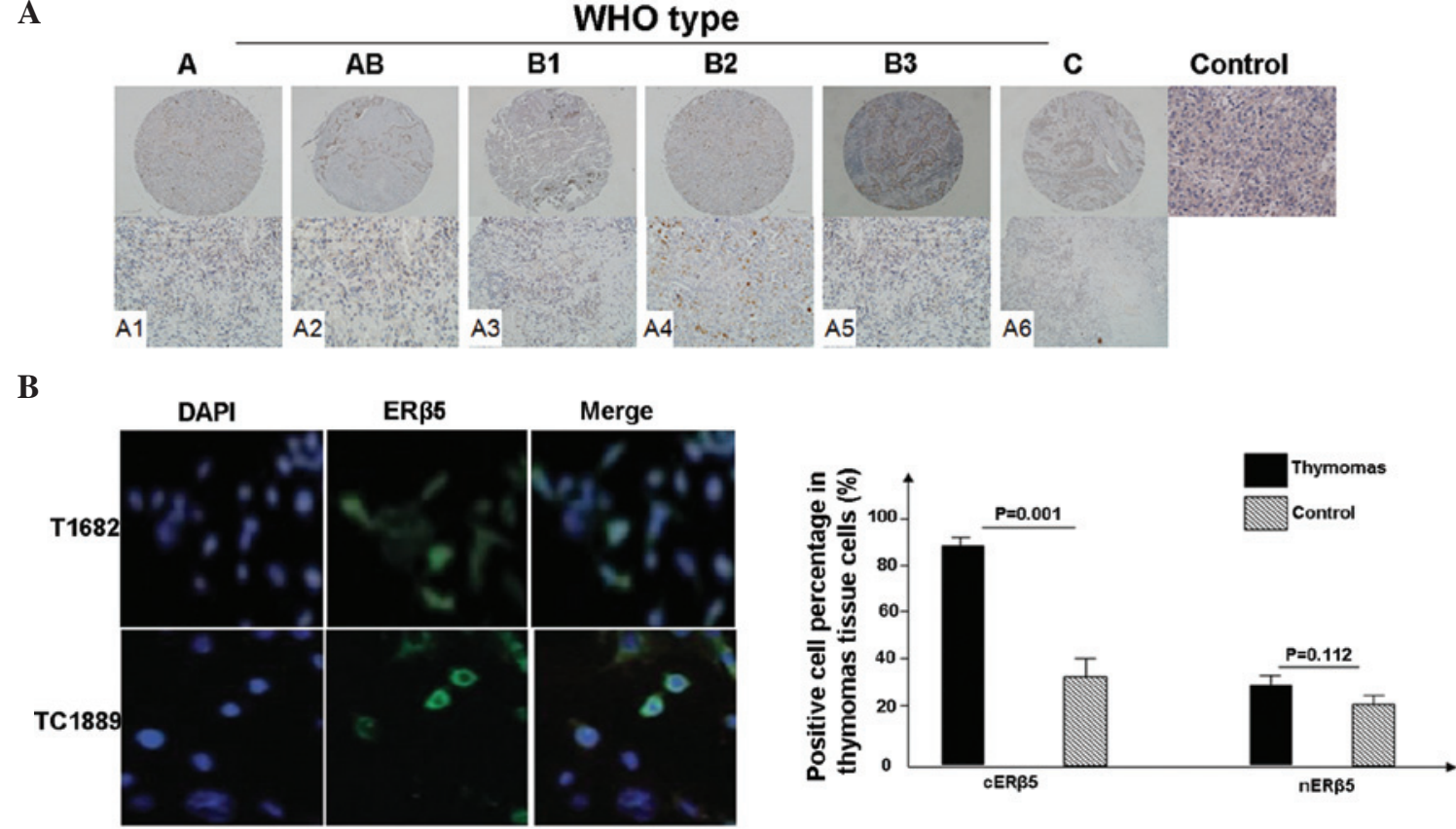

C

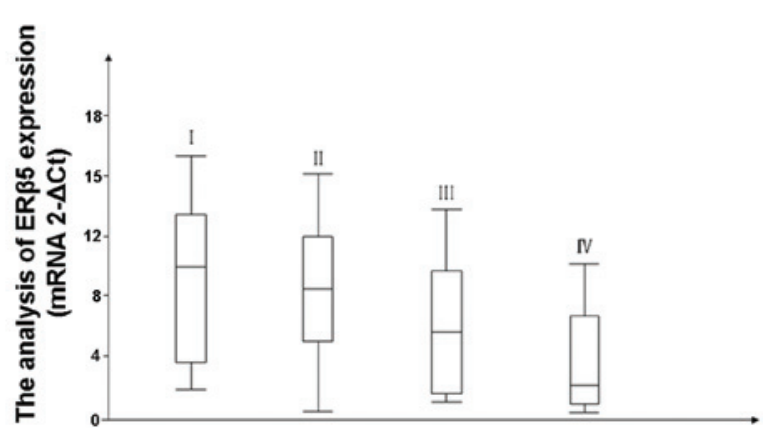

Figure 1. Expression of ER $\beta 5$ in thymic tumors, determined using immunohistochemical tissue microarray staining and reverse transcription-quantitative polymerase chain reaction (RT-qPCR). The immunopositive signal of ER $\beta 5$ protein was graded according to the WHO staging system. (A) ER $\beta 5$ expression was mainly detected in the cytoplasm of thymomas epithelial cells (A1-A6; upper lane magnification, x100; lower lane magnification, x200). Normal thymic tissues without primary antibody staining were used as the control group. Overexpression of cytoplasmic ER $\beta 5$ was observed in thymic carcinomas and thymomas, compared with the normal thymic tissues. (B) ER $\beta 5$ expression was observed in the T1682 and TC1889 cell lines through indirect immunofluorescence. (C) RT-qPCR results, obtained from 49 cases of thymic tumors (clinical stages: I, 7 cases; II, 15 cases; III, 15 cases; and IV, 12 cases). Data for benign tissue samples are not shown. The results revealed that the mean level of ER $\beta 5$ gene expression was lower in advanced clinical stages. ER $\beta 5$, estrogen receptor $\beta 5$.

A

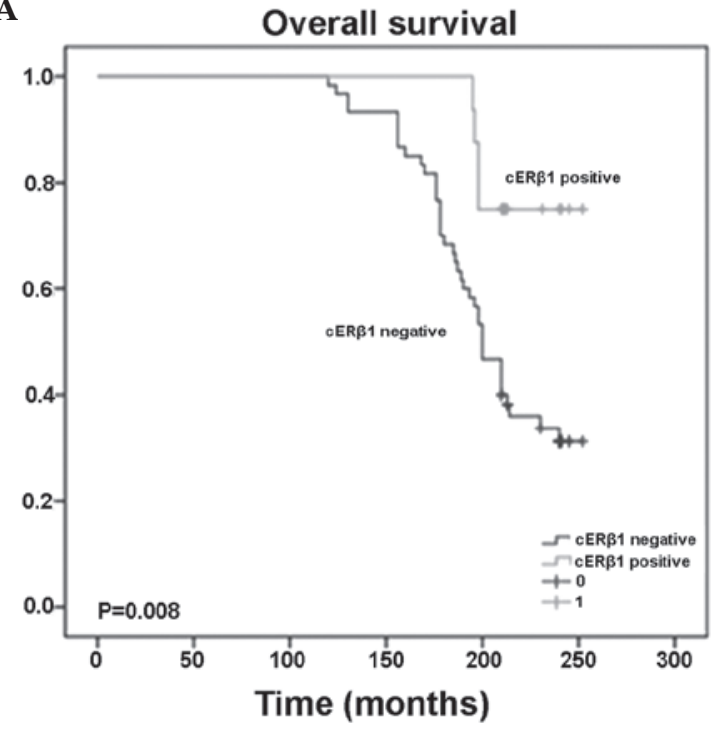

B

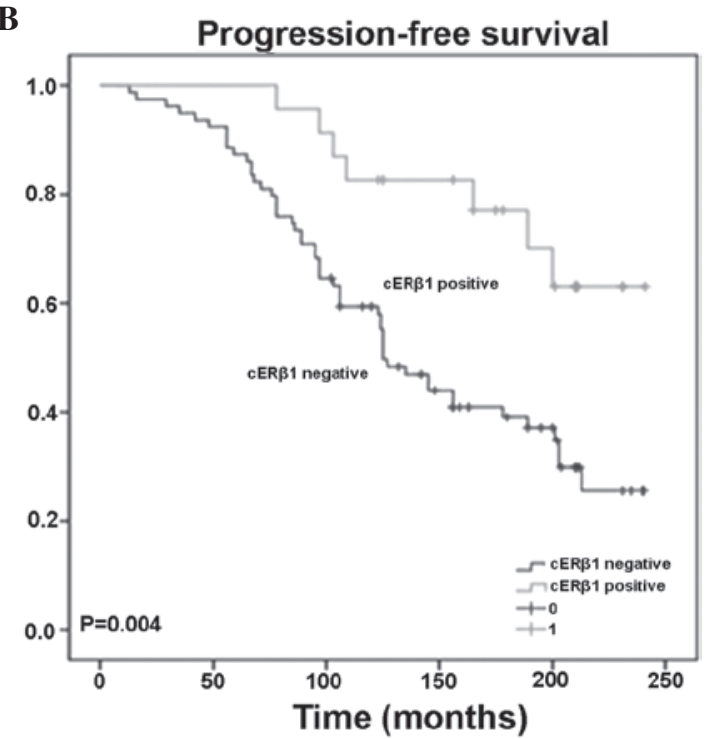

Figure 2. Kaplan-Meier survival estimate curves, showing the (A) overall survival and (B) progression-free survival of patients with thymomas and thymic carcinomas, exhibiting negative cER $\beta 5$ expression. ER $\beta 5$, estrogen receptor $\beta 5$. 
$102 / 103$ cases), with only one case presenting negative staining. In addition, $87.37 \%(90 / 103)$ of the cases were positive for cER $\beta 5,11.62 \%$ of the cases were positive for $n E R \beta 5$ and 15 cases were positive for $n E R \beta 5$ and cER $\beta 5$ (Table I; Fig. 1 A1-A6). In particular, the thymic carcinomas exhibited strong positive staining, while only $38.46 \%$ of normal thymic tissues (10/26; Table I) exhibited positive staining. Furthermore, overexpression of cER $\beta 5$ was observed in the thymic tumors compared with normal thymic tissues, and this difference was statistically significant $(\mathrm{P}=0.001)$; by contrast, $\mathrm{nER} \beta 5$ was not overexpressed in thymic tumors $(\mathrm{P}=0.112$; Table I). Similar results were observed in the T1682 and TC1889 cell lines following IIFA (Fig. 1B).

mRNA quantification was conducted during RT-qPCR, and the results were compared against $\beta$-actin, which was used as the internal reference gene. The ER $\beta 5$ expression levels ranged between 0.468 and 13.292 (median, 5.672; data not shown). In advanced clinical stages, the mean level of ER $\beta 5$ gene expression was lower (Fig. 1C).

Association between cER $\beta 5$ or $n E R \beta 5$ expression levels and patient characteristics. The association between ER $\beta 5$ expression and a range of standard patient characteristics were investigated and are listed in Table II. No positive correlation was detected between cER $\beta 5$ expression and patient characteristics, including gender, age and tumor sizes $(\mathrm{P}=0.245, \mathrm{P}=0.514$ and $\mathrm{P}=0.614$, respectively). Notably, although no statistically significant association was observed between tumor sizes and cER $\beta 5$ expression, the latter was demonstrated to be important in the progression of thymic tumors (Table II).

In addition, no statistically significant association was determined between $\mathrm{nER} \beta 5$ expression and patient characteristics.

Association of ER 35 staining with histological subtype and stage. Since cER $\beta 5$ was overexpressed in the thymic tumors, a statistically significant correlation was observed between cER $\beta 5$ expression and thymoma subtypes $(\mathrm{P}=0.024$; Table III), which presented a particularly strong positive expression in thymic carcinomas. In addition, a statistically significant difference was identified between cER $\beta 5$ staining and thymic tumor stages $(\mathrm{P}=0.003)$; however, a negative correlation was observed (Table III; R=-0.376).

By contrast, no statistically significant differences were observed between nER $\beta 5$ staining and thymomas subtypes or stages ( $\mathrm{P}=0.653$; data not shown).

Kaplan-Meier plot results of TMA analysis. The TMA analysis revealed that cER $\beta 5$ staining was significantly associated with improved OS, whereas nER $\beta 5$ immunoreactivity was not associated with OS (data not shown). In addition, cER $\beta 5$ staining was correlated with improved PFS, which implied that cER $\beta 5$ had a negative biological effect in the development of thymic tumors (Fig. 2).

\section{Discussion}

Exposure to sex steroid hormones, for instance during estrogen therapy, results in thymic atrophy and loss of cellularity in animals $(18,20,21)$. Thymic atrophy induced by estrogens contributes towards certain complicated and unclear mechanisms. A large number of studies have reported that estrogen is involved in biological functions in human and animal organs through estrogen receptors, including ER $\alpha$ and $E R \beta$ (which has at least five isoforms, such as ER $\beta 5$ ) (22-24). At present, controversial findings exist on the expression of estrogen receptors in thymic tumors, since a number studies reported overexpression of ER $\beta$ in these tumors, whereas others studies obtained contradictory results $(11,12,13,19)$.

In the present study, the expression of ER $\beta 5$ was investigated by immunohistochemistry. Overexpression of ER $\beta$ was identified and strong evidence was provided on the controversial function of estrogen receptors in thymic tumors; however, the expression of ER $\alpha$ was not investigated in the present study.

To the best of our knowledge, the present study is the first to compare the protein expression levels of ER $\beta 5$ in specimens from a cohort of patients with thymic tumors $(n=103)$. The immunohistochemical expression of ER $\beta 5$ was analyzed in a set of TMAs using an ER $\beta 5$ specific antibody. The results revealed that ER $\beta 5$ was overexpressed and predominantly located in the cytoplasm of thymic tumors, which indicated the important role of this receptor in the progression of thymic tumors. Furthermore, the present study identified statistically significant differences between cER $\beta 5$ expression and thymic tumor subtypes and stages. Notably, a negative correlation was identified between a high expression of cER $\beta 5$ and tumor stages $(R=-0.376)$, indicating that $c E R \beta 5$ may inhibit thymic tumor progression, providing an insight into the estrogen biological mechanism.

As previously reported (25-27), the classic hormonal mechanism involves the binding of estrogens to ERs in the nucleus, thus promoting the association with specific estrogen response elements in the promoters of target genes. At the same time, ERs regulate the expression of numerous genes without directly binding to DNA, but through protein-protein interactions with certain factors, such as phosphoinositide 3-kinase. According to the results of the present study, ER $\beta 5$ was mainly localized in the cytoplasm, which may indicate that estrogen activated cER $\beta 5$ by protein-protein interaction signaling and then inhibited thymic tumor development.

Further analysis using Kaplan-Meier plots revealed that a high expression of cER $\beta 5$ was a significant prognostic factor of thymic tumors. In addition, the present study indicated that high cER $\beta 5$ expression in thymic tumors was correlated with longer OS and PFS, which was in accordance with previous results $(18,20,21,23,28,29)$. However, the fact that cER $\beta 5$ was overexpressed in thymic tumors, while having an inhibiting biological effect, suggested that $c E R \beta 5$ may be involved in other functions of the thymic tumor development and progression. The results of the present study indicated that the underlying mechanism of estrogen may be complex in thymic tumor development and requires further investigation.

Due to difficulties in the identification of ER $\beta$ isoforms in human thymic tumors, as well as other factors, ER $\beta$ variants have not been previously reported in detail. To the best of our knowledge, in the present study, ER $\beta 5$ was identified in thymic tumor tissues for the first time; however, it was unclear whether other ER $\beta$ isoforms were also expressed, as reported in some cancer tissues, including breast and prostate cancer (28-30). The results of the present study demonstrated that estrogen exerts a biological effect on thymic tumors through ER $\beta 5$, at 
least. Furthermore, the underlying mechanism may involve protein-protein interaction signaling in the thymic tumor cell cytoplasm, although this remains unclear.

In conclusion, the present study suggested that, in part, ER 35 -mediated functions may be a potential underlying mechanism through which estrogens alter susceptibility to thymic tumors. In order to develop more selective and specific ER modulators for the treatment of thymic tumor patients, further studies are required on ligand activation of ER $\beta 5$-mediated functions in thymic tumor patients.

\section{References}

1. Ishibashi H, Suzuki T, Suzuki S, et al: Sex steroid hormone receptors in human thymoma. J Clin Endocrinol Metab 88: 2309-2317, 2003.

2. Wang C, Dehghani B, Magrisso IJ, et al: GPR30 contributes to estrogen-induced thymic atrophy. Mol Endocrinol 22: 636-648, 2008.

3. Pennell LM, Galligan CL and Fish EN: Sex affects immunity. J Autoimmun 38: J282-J291, 2012.

4. Hirahara H, Ogawa M, Kimura M, et al: Glucocorticoid independence of acute thymic involution induced by lymphotoxin and estrogen. Cell Immunol 153: 401-411, 1994.

5. Offner $\mathrm{H}$ and Polanczyk M: A potential role for estrogen in experimental autoimmune encephalomyelitis and multiple sclerosis. Ann NY Acad Sci 1089: 343-372, 2006.

6. Shames RS: Gender differences in the development and function of the immune system. J Adolesc Health 30 (Suppl): 59-70, 2002.

7. Panchanathan R and Choubey D: Murine BAFF expression is up-regulated by estrogen and interferons: implications for sex bias in the development of autoimmunity. Mol Immunol 53: 15-23, 2013.

8. Do Y, Ryu S, Nagarkatti M and Nagarkatti PS: Role of death receptor pathway in estradiol-induced T-cell apoptosis in vivo. Toxicol Sci 70: 63-72, 2002.

9. Hengartner MO: The biochemistry of apoptosis. Nature 407: 770-776, 2000.

10. Okasha SA, Ryu S, Do Y, McKallip RJ, et al: Evidence for estradiol-induced apoptosis and dysregulated $\mathrm{T}$ cell maturation in the thymus. Toxicology 163: 49-62, 2001.

11. Zoller AL, Schnell FJ and Kersh GJ: Murine pregnancy leads to reduced proliferation of maternal thymocytes and decreased thymic emigration. Immunology 121: 207-215, 2007.

12. Mimae T, Tsuta K, Takahashi F, et al: Steroid receptor expression in thymomas and thymic carcinomas. Cancer 117: 4396-4405, 2011.

13. Collins F, MacPherson S, Brown P, et al: Expression of oestrogen receptors, $E R \alpha, E R \beta 5$ and $E R \beta$ variants, in endometrial cancers and evidence that prostaglandin $\mathrm{F}$ may play a role in regulating expression of ER $\alpha$. BMC Cancer 9: 330, 2009.

14. Leung YK, Mak P, Hassan S and Ho SM: Estrogen receptor (ER)-beta isoforms: a key to understanding ER-beta signaling. Proc Natl Acad Sci USA 103: 13162-13167, 2006.
15. Murphy LC, Peng B, Lewis A, et al: Inducible upregulation of oestorgen receptor-betal affects oestrogen and tamoxifen responsiveness in MCF7 human breast cancer cells. J Mol Endocrinol 34: 553-566, 2005.

16. Marx A and Müller-Hermelink HK: From basic immunobiology to the upcoming WHO-classification of tumors of the thymus. The Second Conference on Biological and Clinical Aspects of Thymic Epithelial Tumors and related recent developments. Pathol Res Pract 195: 515-533, 1999.

17. Yamakawa Y, Masaoka A, Hashimoto T, et al: A tentative tumor-node-metastasis classification of thymoma. Cancer 68: 1984-1987, 1991.

18. Breinig M, Mayer P, Harjung A, et al: Heat shock protein 90 -sheltered overexpression of insulin-like growth factor 1 receptor contributes to malignancy of thymic epithelial tumors. Clin Cancer Res 17: 2237-2249, 2011.

19. Moser B, Janik S, Schiefer AI, et al: Expression of RAGE and HMGB1 in thymic epithelial tumors, thymic hyperplasia and regular thymic morphology. PLoS One 9: e94118, 2014.

20. Olde B and Leeb-Lundberg LM: GPR30/GPER1: searching for a role in estrogen physiology. Trends Endocrinol Metab 20: 409-416, 2009.

21. Lang TJ: Estrogen as an immunomodulator. Clin Immunol 113: 224-230, 2004

22. Spencer-Segal JL, Tsuda MC, Mattei L, Waters EM, et al: Estradiol acts via estrogen receptors alpha and beta on pathways important for synaptic plasticity in the mouse hippocampal formation. Neuroscience 202: 131-146, 2012.

23. Hartman J, Ström A and Gustafsson JA: Current concepts and significance of estrogen receptor $\beta$ in prostate cancer. Steroids 77: 1262-1266, 2012.

24. Cammarata PR, Flynn J, Gottipati S, et al: Differential expression and comparative subcellular localization of estrogen receptor beta isoforms in virally transformed and normal cultured human lens epithelial cells. Exp Eye Res 81: $165-175,2005$.

25. Loven MA, Wood JR and Nardulli AM: Interaction of estrogen receptors $\alpha$ and $\beta$ with estrogen response elements. Mol Cell Endocrinol 181: 151-163, 2001

26. Sheldahl LC, Shapiro RA, Bryant DN, et al: Estrogen induces rapid translocation of estrogen receptor $\beta$, but not estrogen receptor $\alpha$, to the neuronal plasma membrane. Neuroscience 153: 751-761, 2008 .

27. Mhyre AJ and Dorsa DM: Estrogen activates rapid signaling in the brain: Role of estrogen receptor $\alpha$ and estrogen receptor $\beta$ in neurons and glia. Neuroscience 138: 851-858, 2006.

28. Scobie GA, Macpherson S, Millar MR, et al: Human oestrogen receptors: differential expression of ER alpha and beta and the identification of ER beta variants. Steroids 67: 985-992, 2002.

29. Omoto Y, Kobayashi S, Inoue S, et al: Evaluation of oestrogen receptor $\beta$ wild-type and variant protein expression and relationship with clinicopathological factors in breast cancers. Eur J Cancer 38: 380-386, 2002.

30. Wang $X$ and Kilgore MW: Signal cross-talk between estrogen receptor alpha and beta and the peroxisome proliferator-activated receptor gamma1 in MDA-MB-231 and MCF-7 breast cancer cells. Mol Cell Endocrinol 194: 123-133, 2002. 